\title{
A mystery: tuberculous peritonitis
}

\section{Introduction}

Tuberculosis (TB) is a common and major health problem especially in developing countries. ${ }^{1}$ Tuberculous peritonitis (TBP) is an uncommon presentation of TB without any other debilitating diseases such as cirrhosis, diabetes and chronic renal failure on continuous ambulatory peritoneal dialysis. ${ }^{2}$

\section{Case report}

A 49-year old woman was referred to our department with weight loss and abdominal pain. Abdominal ultrasound examination confirmed the presence of ascites but there was no organomegaly or mass detected. Serum ascites albumin gradient was 0.6. Ascitic fluid cell count was $10 / \mathrm{mm}^{3}$, predominantly lymhocytes. Ascitic fluid cytological analysis did not help the diagnosis. Her further diagnostic procedures including esophagogastroduedonoscopy, colonoscopy, gynecological examination were normal. The chest and abdomen computed tomographic scan revealed only the presence of gross ascitic fluid. Serum CA 125 level was $336 \mathrm{u} / \mathrm{ml}(0-35)$. Ascitic fluid ADA level was 47.26U/L (0-40). Albeit the tests done we did not find the etiology of the ascites and decided to do laparoscopic examination. In the laporoscopic examination, large macro- and micro-nodular degeneration of the visceral and parietal peritoneum with the presence of white plaques and omental thickening was seen (Figure 1).

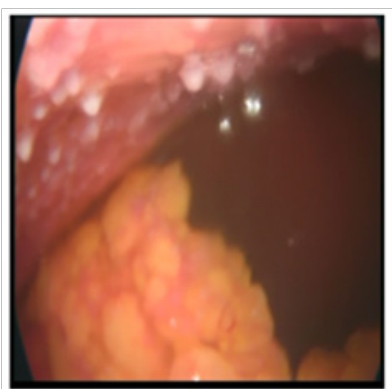

ง)

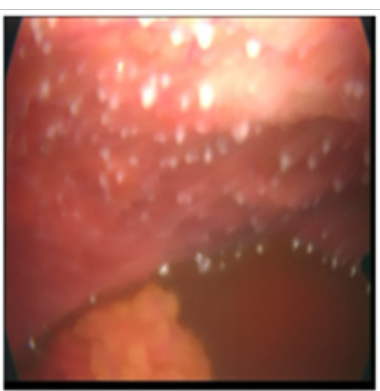

в)
Figure I Laporoscopic image of our case. Multiple white miliary nodules are seen on the parietal peritoneum.

Histological examination of the peritoneal biopsies showed epithelial granuloma with the presence of Langhans-type giant cells and a wide area of caseous necrosis, but without acid-fast bacilli. $M$. tuberculosis PCR (Polymerase Chain Reaction), performed in tissue was negative. By the council decision 4-drug regimen of isoniazid, rifampicin, pyrazinamide, and streptomycin was started to patient. After six months a control abdominal ultrasound examination confirmed the absence of ascites.

\section{Discussion}

Tuberculous peritonitis accounts for a small portion of all tuberculous cases, but it has been increasing worldwide, including developed countries. The peritoneum is a relatively common extrapulmonary site for tuberculosis and has diverse and non-specific symptoms. No single test is adequate for the it's diagnosis. Peritoneal involvement accounts for $0.1-0.7 \%$ of all tuberculous patients. ${ }^{3}$
Volume 7 Issue 3 - 2017

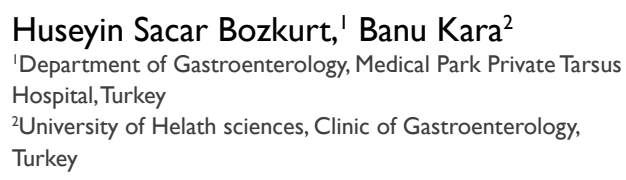

Correspondence: Hüseyin Sancar Bozkurt, Private Tarsus Medical Park Hospital, Gastroenterology, Turkey, Tel 009032424I4I4I, Fax 0090505448229I,

Email sancarb79@gmail.com

Received: November 29, 2016 | Published: August 16, 2017

Patients with tuberculous peritonitis present insidious nature and nonspecific symptoms that make diagnosis difficult. Also intestinal obstruction or perforation, which may require surgery, rarely occurs in patients with tuberculous peritonitis. ${ }^{4}$ Diagnosis of TBP remains an ongoing dilemma requiring a high index of clinical suspicion. ${ }^{5}$ Diagnostic laparoscopy or laparotomy is usually necessary for definitive diagnosis. ${ }^{6-8}$ The main treatment option for tuberculous peritonitis is pharmalogical therapy. The regimens curative for pulmonary tuberculosis are also effective for tuberculous peritonitis. A two months initial phase of isoniazid(INH), rifampicin (RIF), pyrazinamide and ethambutol, followed by the administrations of INH and RIF for another 4 months, may be sufficient in most cases of tuberculous peritonitis Laparoscopy and peritoneal biopsy are still the most reliable, quick and safe methods for the diagnosis of TBP.

\section{Acknowledgements}

None.

\section{Conflicts of Interest}

There is no conflict of interest.

\section{Funding}

None.

\section{References}

1. Butt T, Karamat KA, Ahmad RN. Advances in diagnosis of tuberculosis. Pak J Pathol. 2001;12:1-3.

2. Demir K, Okten A, Kaymakoglu S, D Dincer, et al. Tuberculous peritonitis - reports of 26 cases, detailing diagnostic and therapeutic problems. Eur J Gastroenterol Hepatol. 2001;13(5):581-585.

3. Mehta JB, Dult A, Harvill L, et al. Epidemiology of extrapulmonary tuberculosis: a comparative analysis with preAIDS era. Chest. 1991;99(5): 1134-1138. 
4. Sanai FM, Bzeizi KI. Systemic review: tuberculous peritonitispresenting features, diagnostic strategies and treatment. Aliment Pharmacol Ther. 2005;22(8):685-700.

5. Khan R, Abid S, Jafri W, et al. Diagnostic dilemma of abdominal tubercolosis in non-HIV patients: An ongoing challange for physicians. World J Gastroenterol. 2006;12(39):6371-6375.

6. Piura B, Rabinovich A, Leron E, et al. Peritoneal tuberculosis mimicking ovarian carcinoma with ascites and elevated serum CA-125: case report and review of literature. Eur J Gynaecol Oncol. 2002;23(2):120-122.
7. Uzunkoy A, Harma M, Harma M. Diagnosis of abdominal tuberculosis: experience from 11 cases and review of the literature. World $J$ Gastroenterol. 2004;10(24):3647-3649.

8. Tinelli A, Malvasi A, Vergara D, et al. Abdomino-pelvic tuberculosis in gynecology: Laparoscopic and new laboratory findings. ANZ J Obstetr Gynecol. 2008;48(1):90-95. 